\title{
GalnPIGaAs DUAL JUNCTION SOLAR CELLS ON Ge/Si EPITAXIAL TEMPLATES
}

\author{
Melissa J. Archer ${ }^{1}$, Daniel C. Law², Shoghig Mesropian², Andreea Boca², Moran Haddad², Corinne Ladous ${ }^{3}$, Richard R. \\ King $^{2}$, Harry A. Atwater ${ }^{1}$ \\ ${ }^{1}$ Califomia Institute of Technology, 1200 East Califomia Boulevard, Pasadena, Califomia 91125, USA \\ ${ }^{2}$ Spectrolab Engineering Inc., 12500 Gladstone Avenue, Sylmar, Califomia 91342, USA \\ ${ }^{3}$ Aonex Corporation, 129 North Hill Avenue, Suite 108, Pasadena, California 91106, USA
}

\begin{abstract}
In this study, we report synthesis of large area $\left(>2 \mathrm{~cm}^{2}\right)$ crack-free GalnP/GaAs double junction solar cells on 50 $\mathrm{mm}$ diameter $\mathrm{Ge} / \mathrm{Si}$ templates fabricated using wafer bonding and ion implantation induced layer transfer techniques. Defect removal from the template film and film surface prior to epitaxial growth was found to be critical to achievement of high open circuit voltage and efficiency. Cells grown on templates prepared with chemical mechanical polishing in addition a wet chemical etch show comparable performance to control devices grown on bulk Ge substrates. Current-voltage (I-V) data under AM 1.5 illumination indicate that the short circuit current is comparable in templated and control cells, but the open circuit voltage is slightly lower (2.08V vs. $2.16 \mathrm{~V})$. Spectral response measurements indicate a drop in open circuit voltage due to a slight lowering of the top GalnP cell band gap. . The drop in band gap is due to a difference in the indium composition in the two samples caused by the different miscut $\left(9^{\circ}\right.$ vs. $\left.6^{\circ}\right)$ of the two kinds of substrates.
\end{abstract}

\section{INTRODUCTION}

To achieve an optimal bandgap sequence for conversion of the solar spectrum in four or more junction solar cells, lattice-mismatched structures will be required. While current metamorphic growth techniques are proving useful in three junction cell applications[1-4], they are limited in the degree of mismatch that they can accommodate. Wafer bonding, on the other hand, can accommodate any degree of lattice mismatch and isolate the defects at the bonded interface between mismatched layers. In this way, materials with a wide variety of lattice parameters can be integrated into a single device.

In our approach to development of a near optimal four-junction solar cell, we use templates for subcell growth employing two lattice parameters, and two bonded interfaces. The first brings together our active material systems, which are based on the GaAs and InP lattice constants. The second allows us to utilize a Si substrate as the overall cell substrate rather an expensive InP substrate. . The final structure will consist of a GalnP/GaAs/GalnAsP/GalnAs four junction solar cell on a Si substrate. Toward this end, we have developed a process for fabrication and characterization of GalnP/GaAs dual junction solar cells on $\mathrm{Ge} / \mathrm{Si}$ epitaxial templates. In other work, we have demonstrated other key components of multijunction cell development, including high quality InGaAs solar cells on InP/Si templates[5] as well as low-resistance bonded interfaces between GaAs and InP wafers[6].

Wafer bonding and layer transfer allow highquality single crystal films of one material to be directly bonded to another material. In this process, $\mathrm{He}^{2+}$ and/or $\mathrm{H}^{+}$are implanted into the device material of choice, for example $\mathrm{Ge}$ in this work. Then, the surfaces of the device material and the handle substrate are cleaned and plasma activated. The two materials are then bonded together and with pressure and heat, the implanted ions coalesce and form a crack at the peak implant depth. After the process is complete, a thin film, whose thickness corresponds to the peak implant depth, is bonded to the

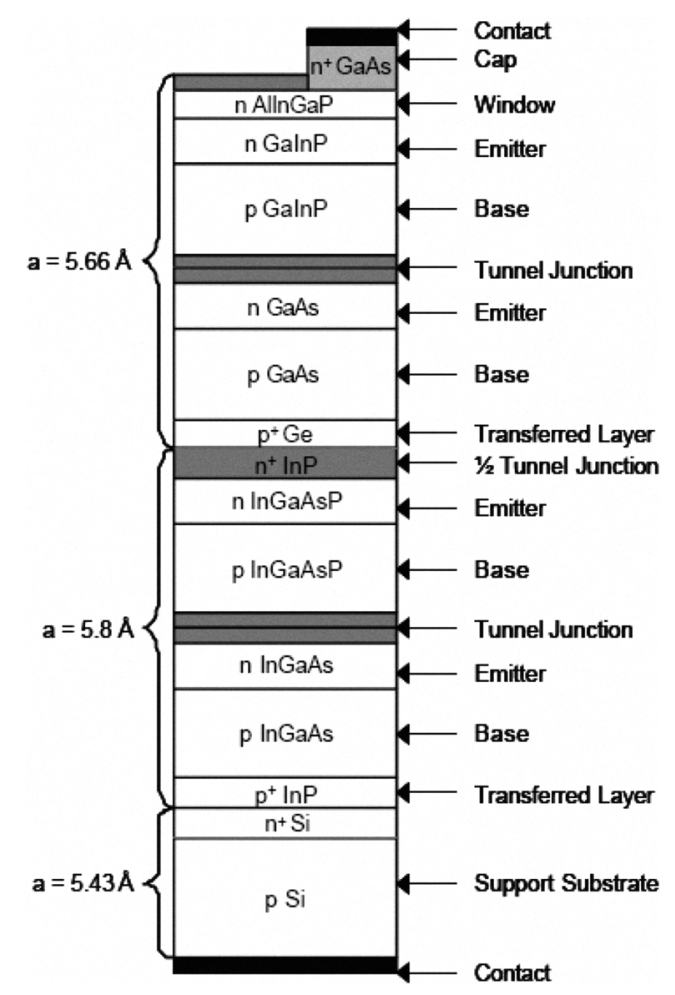

Fig. 1. Schematic of the proposed wafer bonded four-junction solar cell, where a denotes the lattice constant of the materials.

handle substrate. We have demonstrated up to $50 \mathrm{~mm}$ wafer layer transfer as shown in Figure 2. 

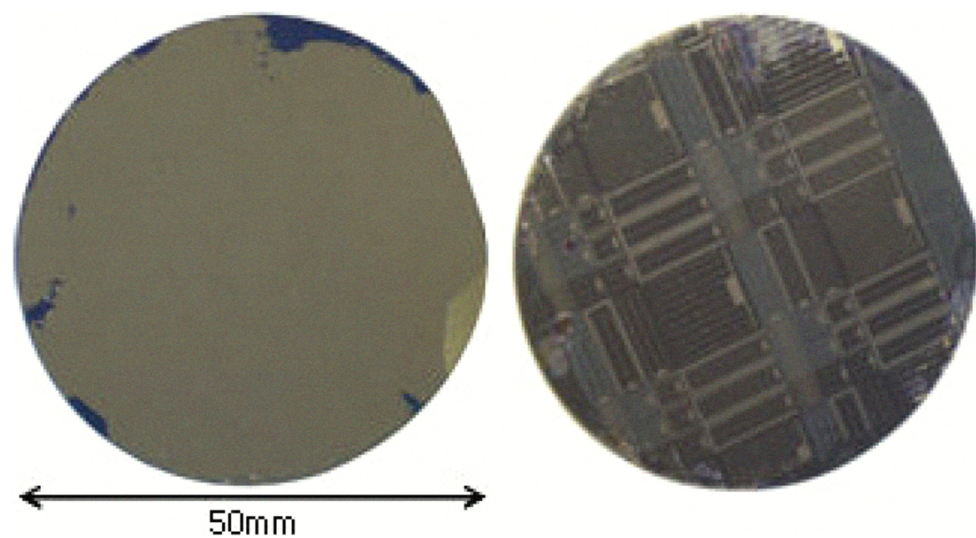

Fig. 2. Optical micrographs of a full $50 \mathrm{~mm}$ Ge/Si template made with layer transfer and wafer bonding (left), and GalnP/GaAs solar cells grown on a Ge/Si template (right).

\section{EXPERIMENTAL PROCEDURES}

$\mathrm{Ge} / \mathrm{Si}$ templates were fabricated using implantation of $\mathrm{H}^{+}$into $\mathrm{Ge}$ substrates. These implanted substrates were then hydrophobically bonded to $\mathrm{Si}$ substrates. At elevated temperature and pressure, the implanted $\mathrm{Ge}$ wafers split along the peak implantation position.

With $\mathrm{Ge}$ on Si epitaxial templates, the astransferred film has an RMS roughness of $\sim 20 \mathrm{~nm}$ and has a near surface region with a high concentration of residual crystal defects from the ion implantation process. If they are not removed, these defects lead to threading dislocations that propagate from the template into the epitaxial films, as shown in Fig. 3(a). To prepare these templates for epitaxial growth, we must remove the damage layer and minimize the surface roughness. The damaged layer is removed with a simple wet etch, dilute $\mathrm{CP}-4$, and the surface roughness is abated with a touch polish on a Logitech PM5 polisher. After this processing, the template has an RMS roughness of $<1 \mathrm{~nm}$ and the near surface damaged region is gone, as shown in Figure 3. Once the epitaxial template is prepared, we process dual junction GalnP/GaAs solar cells on $\mathrm{Ge} / \mathrm{Si}$ templates

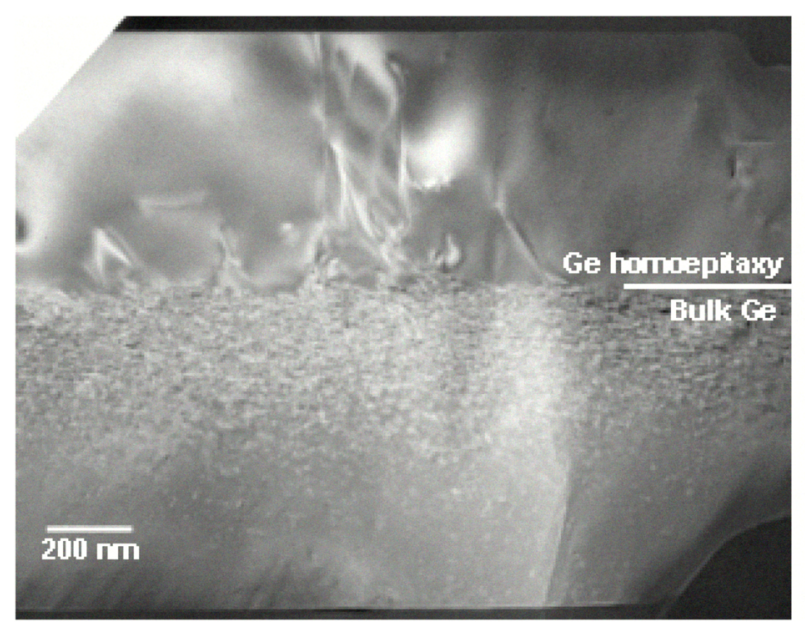

as well as control bulk epi-ready Ge wafers. The resulting cell structure is shown schematically in Figure 4 and experimentally at right in Fig. 2.

\section{RESULTS}

After cell processing, we characterize cells via spectral response and light $\mathrm{I}-\mathrm{V}$ measurements. The data are shown in Figure 5. The spectral response measurements, indicate comparable performance in cells grown on $\mathrm{Ge} / \mathrm{Si}$ templates as in cells grown on bulk Ge before the AR coating is applied. After the application of the AR coating, the GaAs cell shows a significant drop in performance relative to the control cell. In addition, there is a shift of approximately $60 \mathrm{meV}$ in the band gap of the GalnP cell on the $\mathrm{Ge} / \mathrm{Si}$ template. This can be explained by the different miscut of $\mathrm{Ge}$ wafers used in making the template as in the bulk control wafer. The bulk $\mathrm{Ge}$ wafer had a miscut of $6^{\circ}$, whereas the $\mathrm{Ge}$ wafer used in making the $\mathrm{Ge} / \mathrm{Si}$ template was $9^{\circ}$. The miscut of the $\mathrm{Ge}$ growth surface changes the adsorption of indium; higher miscut typically lowers the incorporated indium composition under the same growth conditions[7]. To probe this more carefully, high-resolution $X$-ray diffraction rocking curves were performed about the central $\mathrm{Ge}(001)$ peak. These measurements show that

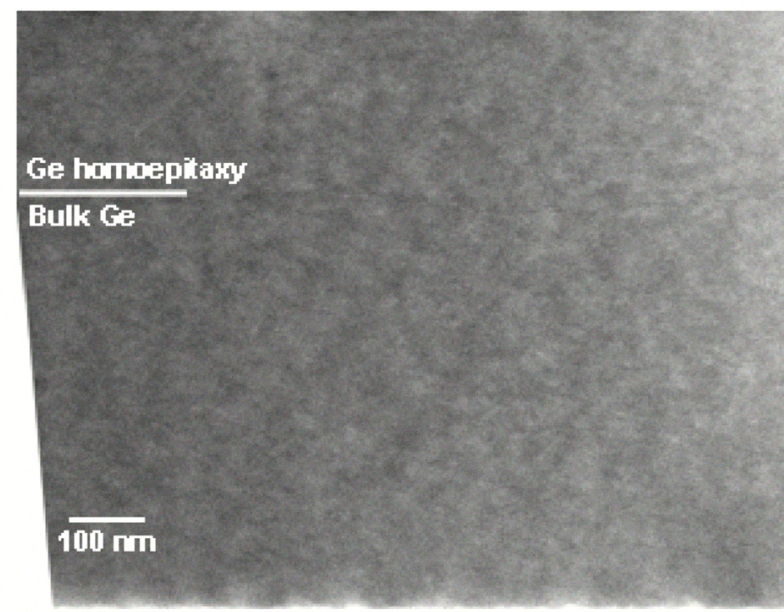

Fig. 3. Cross-sectional transmission electron microscopy images of Ge homoepitaxy on a Ge/Si template without damage removal (left) and with damage removal (right). The white line is at the interface of the substrate and the homoepitaxy. 


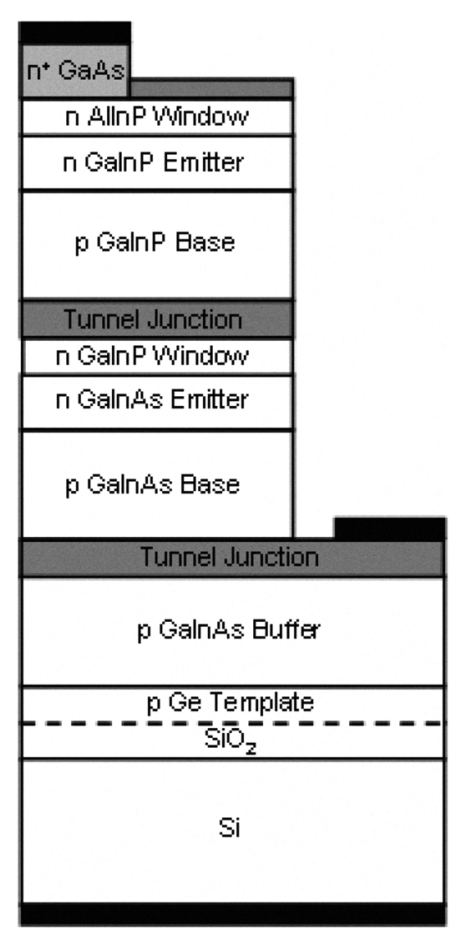

Figure 4. Schematic cross-section of the dual junction solar cell grown and processed by Spectrolab. The bonded interface is shown by a dashed line.
In the light I-V data, the short circuit current is comparable between some control cells and the template sample. In addition, the fill factors are the same between the control and template grown cells. However, the open circuit voltage is lower in the cells grown on $\mathrm{Ge} / \mathrm{Si}$, which is primarily due to the lower band gap of the top cell. Overall, after AR coating, the control cell showed an efficiency of $17.2-19.9 \%$, whereas the Ge/Si templates had an efficiency of $15.5-15.7 \%$.

\section{CONCLUSIONS}

We have demonstrated high efficiency GalnP/GaAs dual junction solar cells on $\mathrm{Ge} / \mathrm{Si}$ templates. In combination with the results from bottom cells grown on $\mathrm{InP} / \mathrm{Si}$ templates and the low-resistance bonded interfaces, these results enable the fabrication of the full four junction bonded GalnP/GaAs/InGaAsP/InP on Si solar cell.

\section{ACKNOWLEDGEMENTS}

The authors would like to acknowledge the National Renewable Energy Laboratory through subcontract XAT4-33624-10 for support of the Caltech and Spectrolab portions of this work. One of us (MJA) acknowledges fellowship support from the National Science Foundation. Support for TEM work was provided by the Caltech Kavli Nanoscience Institute and Materials Science TEM facilities supported by the MRSEC Program of the National Science Foundation under Award Number DMR-0520565.

\section{REFERENCES} compressively strained, which corresponds to an indium composition of $53 \%$. The GalnP cell on the $\mathrm{Ge} / \mathrm{Si}$ template, however, is lattice matched, corresponding to an indium composition of $49.5 \%$. Increasing the indium composition by $3.5 \%$ corresponds to a decrease of 64 $\mathrm{meV}$ in the band gap[8], which correlates well with our spectral response measurements.

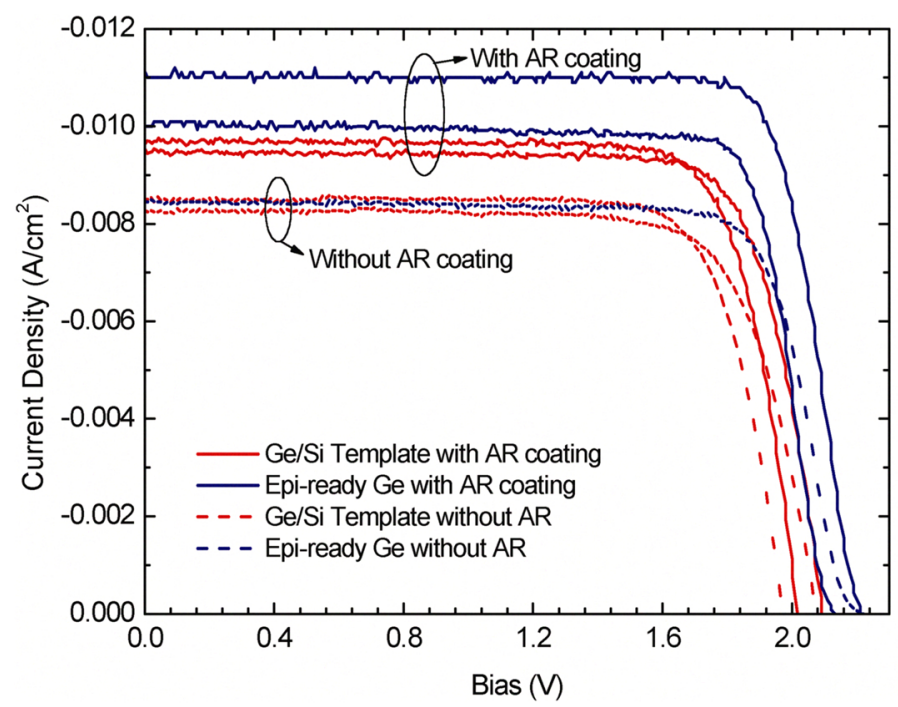

[1] R. R. King, D. C. Law, K. M. Edmondson, C. M Fetzer, G. S. Kinsey, H. Yoon, R. A. Sherif, and N. H. Karam, "40\% efficient metamorphic GalnP/GalnAs/Ge multijunction solar cells," Applied Physics Letters, vol. 90, Apr 2007.

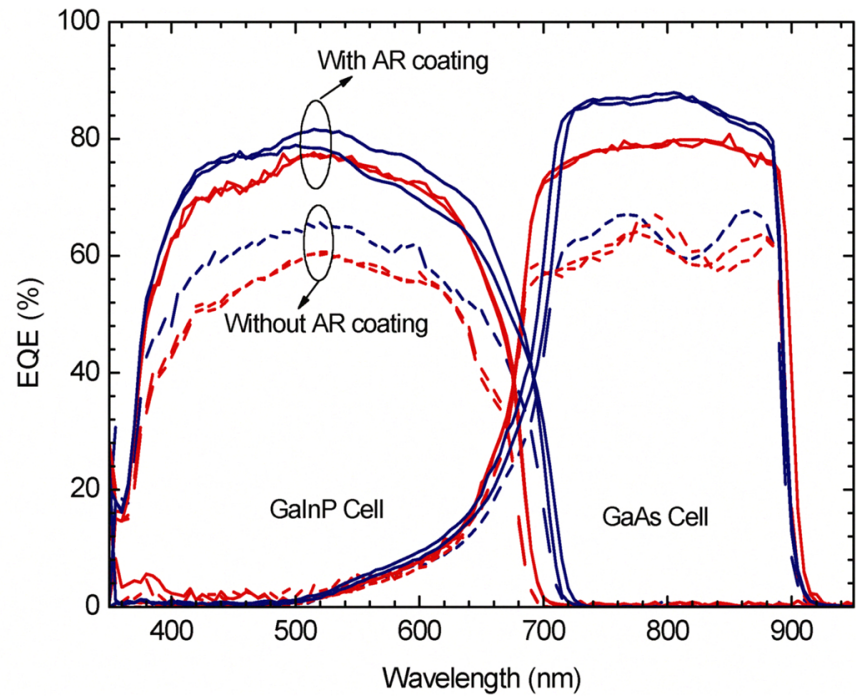

Figure 5. Photovoltaic I-V curves (left) and spectral response (right) for the GalnP/GaAs solar cells grown on Ge/Si epitaxial templates and on a bulk epi-ready Ge substrate. 
[2] C. M. Fetzer, H. Yoon, R. R. King, D. C. Law, T. D. Isshiki, and N. H. Karam, "1.6/1.1 eV metamorphic GalnP/GalnAs solar cells grown by MOVPE on Ge," Journal of Crystal Growth, vol. 276, pp. 48-56, Mar 2005.

[3] M. Wanlass, P. Ahrenkiel, D. Albin, J. Carapella, A. Duda, K. Emery, D. Friedman, J. Geisz, K. Jones, A. Kibbler, J. Kiehl, S. Kurtz, W. McMahon, T. Moriarty, J. Olson, A. Ptak, M. Romero, and S. Ward, "Monolithic, Ultra-Thin GalnP/GaAs/GalnAs Tandem Solar Cells," in 4th World Conference on Photovoltaic Energy Conversion, Waikoloa, Hawaii, 2006, pp. 729732.

[4] F. Dimroth, U. Schubert, and A. W. Bett, "25.5\% efficient $\mathrm{Ga0} .35 \mathrm{In} 0.65 \mathrm{P} / \mathrm{Ga0} .83 \mathrm{In} 0.17$ as tandem solar cells grown on GaAs substrates," IEEE Electron Device Letters, vol. 21, pp. 209-211, May 2000.

[5] J. M. Zahler, K. Tanabe, C. Ladous, T. Pinnington, F. D. Newman, and H. A. Atwater, "High efficiency InGaAs solar cells on Si by $\ln P$ layer transfer," Applied Physics Letters, vol. 91, Jul 2007.

[6] K. Nakayama, K. Tanabe, and H. A. Atwater, "Improved Electrical Properties of Wafer Bonded p-GaAs/n-InP Interfaces with Sulfide Passivation," Joumal of Applied Physics, (in print), 2007.

[7] J. R. Dong, S. J. Chua, Y. J. Wang, and H. R. Yuan, "Substrate orientation dependence of In composition of AIGalnP epilayers grown by MOCVD," Journal of Crystal Growth, vol. 269, pp. 408-412, Sep 2004.

[8] C. P. Kuo, S. K. Vong, R. M. Cohen, and G. B. Stringfellow, "Effect of Mismatch Strain on BandGap in III-V Semiconductors," Journal of Applied Physics, vol. 57, pp. 5428-5432, 1985. 